\title{
CONHECIMENTO E FORMAÇÃO NAS IES PERIFÉRICAS PERFIL DO ALUNO "NOVO" DA EDUCAÇÃO SUPERIOR
}

\author{
Luiz Percival Leme Britto* \\ Edineuza Oliveira Silva** \\ Katlin Cristina de Castilho*** \\ Tatiane Maria Abreu****
}

Recebido em 02 de setembro de 2008

Aprovado em 09 de setembro de 2008

*Professor do Programa de Mestrado em Educação da Universidade de Sorocaba. E-mail: luis.britto@, uniso.br

**E-mail: edineusa22@yahoo.com.br

***E-mail: katlin_cristina@yahoo.com.br

****E-mail: abreu.tma@gmail.com

Resumo: Considerando a forma como se organiza atualmente a Educação Superior no Brasil, num contexto de forte demanda por conhecimento de caráter instrumental e normativo, voltado para a adequação dos sujeitos, de suas condutas e avaliações às exigências da produção e do consumo urbanos, busca-se avançar o reconhecimento das concepções de conhecimento e de desenvolvimento pessoal do estudante universitário. Para tanto, apresentamos neste trabalho uma análise do campo da Educação Superior no Brasil atual, com ênfase na identificação caracterização de IES periférica e do aluno "novo". Este trabalho apresenta resultados parciais de pesquisa que vem sendo realizadas em torno do tema "Educação superior, cultura escrita e conhecimento".

Palavras-chave: Educação superior. IES periférica. Estudante universitário. Conhecimento.

\section{KNWOLEDGE AND EDUCATION IN THE PERIPHERAL HIGHER EDUCATION INSTITUTIONS: PROFILE OF THE "NEW" UNDERGRADUATE STUDENT}

Abstract: Considering the way in which Higher Education is presently structured in Brazil, in a context characterized by strong demands for normative and instrumental knowledge, aiming to adjust the conducts and evaluations of the subjects to the demands of the market-place, this study seeks the advance of the analysis of the concepts of knowledge and personal development of the university student. We present in this paper an analysis of Higher Education in Brazil, emphasizing the characterization and identification of the peripheral Higher Education Institutions and the "new" student. This work presents partial results of a research that is being done on the theme "Higher Education, Literacy and knowledge".

Key Words: Higher education. Peripheral higher education institutions. Undergraduate student. Knowledge.

\section{Introdução}

A expansão quantitativa de Instituições de Educação Superior (IES) - que se deu, principalmente, a partir da década de 1990 -, em função da intensificação das demandas de formação do trabalhador e das novas conformações 
capitalistas, tem como conseqüência a subdivisão do sistema no campo da Educação Superior.

Neste contexto, identificam-se instituições responsáveis por grande parte da produção de conhecimento intelectual e acadêmico, constituindo-se o principal espaço de circulação do mesmo, e, em contrapartida, outras instituições que se caracterizam por atuar como instituições de formação profissional circunscrita às necessidades do mercado. Estas IES atendem, majoritariamente, um "novo aluno", oriundo de um segmento social que até recentemente não tinha acesso à Educação Superior e que, normalmente, dispõe de condições de estudo limitadas e pouca convivência com objetos intelectuais e artísticos da cultura hegemônica.

Nosso objetivo, no presente estudo, é avançar a compreensão das condições objetivas em que se definem e se realizam os modos de estudo e de aprendizagem deste "aluno novo". ${ }^{1}$ Trata-se de um enfoque ainda pouco freqüente nos estudos em Educação, em especial os que se centram nos processos de ensinoaprendizagem, dada a tendência de tomar o estudante universitário como uma "categoria" única. Não obstante, conforme adverte Zago, referindo estudos de Grignon e Gruel, “a categoria 'estudante' recobre uma diversidade muito grande de situações e, por isso mesmo, revela-se insuficiente para caracterizá-la. Os estudantes não são todos estudantes no mesmo grau e os estudos ocupam um lugar variável em sua vidas". (ZAGO, 2006, p. 230)

\section{A IES Periférica no Interior do Campo da Educação Superior}

A dinâmica de trabalho e de formação intelectual do mundo contemporâneo se caracteriza pela internacionalização e interdependência da economia, em que se destaca a redução da oferta de empregos formais na indústria, o crescimento do setor de serviços e a expansão e diversificação das atividades urbanas. Neste panorama, tornou-se corrente sustentar que a capacitação necessária para as novas condições de trabalho se obtém, principalmente, por meio da maior escolaridade e de maior alfabetismo, o que, por sua vez, tem se refletido do atendimento em todos os níveis da Educação Escolar.

1 As investigações dos autores deste artigo situam-se em torno do tema "Educação superior, cultura escrita e conhecimento", compreendendo quatro projetos: um o do coordenador, um de dissertação de mestrado e dois de iniciação científica. Busca-se, especificadamente, verificar como estudantes de IES periférica: 1. atualizam os conceitos de conhecimento e de estudo em sua vida acadêmica e os efeitos disto sobre suas concepções e expectativas de aprendizagem; 2 . percebem a "autoria do conhecimento" e se relacionam com a noção verdade científica; 2. investem (financeira e intelectualmente) na constituição de acervo pessoal; e 4. relacionam suas experiências culturais e estéticas (formação geral) com a formação intelectual e universitária. 
No que tange especificamente à Educação Superior, o avanço de matrículas é impressionante. Em 1980, houve 1.377.286 de matrículas em todos os cursos superiores presenciais brasileiros: em 1998, este número saltou para 2.125.958 e, em 2001, atingiu a cifra de 3.030.754, dos quais 1.734 .936 estudando no período noturno. Em 2006, o número de matrículas alcançou 4.676.646, sendo 3.467.342, em instituições privadas (INEP/MEC, 2006).

É mister considerar, no entanto, que a expansão das vagas na Educação Superior não tem ocorrido de maneira aleatória, mas em função da profunda transformação do sistema, cuja razão de ser não é mais, ou apenas, a de formar quadros dirigentes da nação e a intelectualidade profissional urbana (modelo que prevaleceu até meados do século XX), mas também a de produzir mão-de-obra especializada (VIEIRA, 2003). Inchado, o sistema se subdivide, criando, de um lado, nichos de excelência e, de outro, grandes conglomerados de treinamento de pessoal para o mercado de trabalho e para a adaptação a determinado tipo de sociedade (CUNHA, 2004; DIAS SOBRINHO, 2004; SGUISSARDI, 2005).

Para Silva e Balzan (2007, p. 234), o mercado tem exigido das IES a formação de profissionais com vasta competência operacional e habilidades comportamentais.

As organizações empresariais, movidas pela concorrência sem limites, exigem dos trabalhadores uma nova postura. Suas atividades funcionais não podem mais se restringir à simples repetição mecânica. Hoje, os profissionais almejados por essas corporações necessitam estar capacitados para um considerável número de competências operacionais, somadas a outras tantas habilidades comportamentais.

É relevante sublinhar que, "num mundo em que aumenta constantemente a competitividade, a educação é cada vez mais canalizada para o desenvolvimento das competências para o mundo do trabalho, e não para a reflexão" (GOERGEN, 1998, p. 63). Em tempos atuais, verifica-se que um tipo específico e limitado de formação profissional, adequado às necessidades neoliberais, tornou-se predominante na Educação Superior. Para vários especialistas, tal concepção de formação intelectual e acadêmica é propulsora de um tipo de conhecimento de caráter instrumental e normativo. (CHAUÍ, 2001; DIAS SOBRINHO, 2002)

Conforme Castanho (2000, p. 36), os fundamentos neoliberais podem ser salientados neste nível de ensino,

porque se orienta não mais para as necessidades da nação, mas para as exigências do mercado; porque se vê como um empreendimento, como tantos outros, sendo preferível que sua iniciativa seja privada, 
não publica; porque sua administração deve atender antes aos requisitos da eficiência gerencial do que aos reclamos da participação política; porque não se vê mais como uma instituição que tem um compromisso para melhorar a vida social, deixando questões como essas ao livre jogo das forças do mercado; e, enfim, neoliberal, porque passa a se definir como um espaço onde o indivíduo busca instrumentos para o seu sucesso na sociedade e não onde a sociedade habilita indivíduos para o seu serviço.

Entendemos, no entanto, que o papel social da universidade deve ir além das necessidades mercantis de simples profissionalização de mão-de-obra. Sua finalidade deveria ser formar cidadãos para o exercício da crítica e do pensamento reflexivo, capazes de interagir com conhecimentos sofisticados com independência. $\mathrm{O}$ compromisso das universidades seria com o desenvolvimento de uma sociedade justa e comprometida com a cidadania e com a democracia.

Para Dias Sobrinho e Goergen (2006, p. 38) esse compromisso social não desconsidera a importância de capacitação profissional de alto nível e de força de trabalho bem treinadas. Sem dúvida, a capacitação profissional tem valor público e pessoal, como parte da formação integral, de modo que é também por este princípio que se devem orientar os objetivos fundamentais da sociedade democrática. O que não pode ocorrer, contudo, é a limitação da formação profissional à capacitação técnica e sua associação ao progresso individual da propriedade privada, o que suporia a submissão incondicional às determinações do mercado.

Dois aspectos do campo da educação superior merecem destaque para a compreensão da forma atual de sua organização.

O primeiro é o da massificação do acesso, que promove a afluência massiva na Educação Superior de um "novo aluno", oriundo de um segmento social que até há pouco não era "sujeito" deste nível de educação. (ZAGO, 2006; SETTON, 2005; BRITTO, 2005).

A massificação do acesso está relacionada com a sobreposição de uma nova função da Educação Superior às que ela tradicionalmente exerceu: a de produzir a formação institucional e regular dos quadros médios de trabalhadores modernos urbanos, tanto para a indústria como para o setor de serviço (mas, ressalve-se: também o setor secundário, capitalizado e industrializado, está envolvido neste processo, ainda que de forma menos intensa). Esta nova função, por sua vez, articula-se com as demandas do mercado, englobando tanto a oferta de emprego / trabalho, como a organização mesma do sistema produtivo. (MANCEBO, 2004; HADDAD; GRACIANO, 2004) 
O segundo aspecto importante a considerar, diretamente relacionado ao primeiro, é o da mercantilização do ensino. Trata-se de um modo de realização da educação em que a simples divisão entre estatal e privado não é capaz de dar conta. A mercantilização da educação supõe, além do direito privado do exercício educacional, a sua realização como "bem de mercado", como uma mercadoria cujo valor se define em função do tipo de serviço, do prestador do serviço e da possibilidade de compra pelo consumidor / usuário.

Além disso - ou mais exatamente, por causa disso -, a administração da instituição tem suas lideranças transformadas em funcionários de investidores e proprietários e passa a ser regida por parâmetros em que os aspectos científicos e acadêmicos tendem a se subordinar às questões de ordem econômica; a noção mesma de produtividade e de eficiência é, inevitavelmente, determinada pelo lucro, o que supõe a limitação substancial de atividades que sejam deficitárias ou pouco lucrativas, como, por exemplo, a pesquisa de base, os cursos de formação de alto nível, a pós-graduação stricto-sensu, etc.

Conforme Sguissardi (2005, p. 215)

Jamais como hoje a universidade foi pensada como parte da economia. Jamais como hoje o conhecimento, a ciência e a tecnologia foram tão valorizados como mercadoria capital a ser apropriada hegemonicamente pelas grandes corporações globalizadas e no interesse dos países centrais. Se o diagnóstico neoliberal aponta a falta de competitividade como a grande fragilidade da economia, na crise do Estado do Bem-Estar, é essa característica-chave da empresa econômica e do mercado que, aos poucos, vai se implantando na universidade e tornando-se constitutiva de sua identidade. A idéia de uma universidade organizada e gerida nos moldes empresariais, trabalhando com uma semimercadoria no quase-mercado educacional está cada vez mais presente no discurso e nas práticas oficiais das políticas públicas de educação superior.

Neste sentido, a Educação Superior apresenta-se de modo difusão, obrigando o pesquisador a delimitar mais precisamente seu objeto de investigação. Para avançar os estudos sobre formação universitária no contexto atual, há que se considerar que as mudanças acima referidas implicam a diversificação tanto do padrão das instituições universitárias como das funções que competiria a cada uma delas, tomadas como um campo específico ${ }^{2}$.

2 "Campo", para Bourdieu, caracteriza-se como o espaço em que os objetos sociais são disputados por diferentes agentes investidos de saberes específicos, títulos, privilégios, esforços. O campo, assim, se define como "o universo no qual estão inseridos os agentes e as instituições que produzem, reproduzem ou difundem a arte, a literatura ou a ciência. Esse universo é um mundo social como outros, mas que obedece a leis sociais mais ou menos específicas" (BOURDIEU, 2003, p. 20) 
Em linhas gerais, a atual conformação do campo da Educação Superior / universidade compreende:

a) a produção de conhecimento restrita às universidades de ponta (públicas / estatais) e centros de pesquisa;

b) a pesquisa localizada e centralizada, com forte financiamento pela indústria (com centros próprios ou por associação com universidades);

c) a inserção do país no mercado globalizado, com importação de tecnologia, mudança da concepção de produção intelectual nacional e maior dependência externa;

d) a modificação das formas de financiamento e de controle do Estado e criação de instrumentos superiores de revalidação do curso, o que significa a dispensa, pelo Estado, da universidade como lugar privilegiado de produção de conhecimento e investimento na Educação superior de massa;

e) a convivência de um modelo clássico de educação de elite com um ensino superior de massas, ocorrendo seleção ocorre apenas em alguns espaços;

f) a forte expansão da rede de Educação Superior, com e interiorização periferização e significativa ampliação de vagas, coincidindo com a emergência das IES de cunho empresarial e das chamadas universidades corporativas;

g) o desenvolvimento e expansão de Instituições de Educação Superior com finalidade estrita de formação e qualificação de mão de obra;

h) a incorporação de novas profissões ao estatuto de "profissões universitárias";

i) a proletarização das profissões clássicas, com uma nova divisão: os donos das clínicas, escritórios e empresas e os profissionais contratados;

j) a expansão e modificação de função da pós-graduação.

Para Dias Sobrinho (2002, p. 169-170), é possível distinguir três tipos de instituições no que tange à relação público-privado, a qual faz questão de frisar que não se resume à lógica estatal x não-estatal: 1. "as instituições públicas, mantidas tradicionalmente pelo erário, com a responsabilidade de formar cidadãos e profissionais segundo as perspectivas da sociedade"; 2. "as instituições que ainda preservam muito do sentido social e os valores da ciên- 
cia e do conhecimento como valor público, como em geral costumam ser as confessionais e muitas comunitárias"; e 3. "as instituições privadas com nítida e até mesmo declarada orientação mercantilista, [...] empresas educacionais que prioritariamente buscam o maior lucro possível e se inserem francamente no jogo de forças do mercado".

Alerta o pesquisador que, "em função da hegemonia da ideologia do mercado", as instituições públicas estatais têm incorporado valores privados e, impelidas à diversificação de fontes de financiamento, adquirem "uma certa mentalidade própria de empresas". Já as instituições particulares de cunho público, como seriam as confessionais e comunitárias, por necessidade de sobrevivência, falta de suporte estatal e adesão ao modelo mercantil, se vêm na necessidade de adotar medidas ou ações gerenciais próprias da lógica de mercado.

Na mesma direção de Dias Sobrinho, mas com outro propósito (o de identificar um tipo de instituição a que acede o estudante de primeira geração de longa escolaridade), Britto e Torrezan (2002), em estudo preliminar a este, propuseram a seguinte classificação:

1. as grandes universidades públicas, que se constituem em referência nacional;

2. as universidades públicas regionais;

3. as instituições universidades confessionais e comunitárias;

4. as instituições particulares de periferia de grandes centros urbanos;

5. os cursos superiores isolados.

Numa perspectiva bastante distinta, mas que pode ser tomada de modo complementar ao que expõem Dias Sobrinho (2002) e Britto e Torrezan (2002), está a análise de Setton (1999) sobre os cursos universitários de humanidades da Universidade de São Paulo a partir das características sócio-culturais do alunado (origem social e trajetória acadêmica). Advertindo que sua consideração não inclui nenhum julgamento sobre a qualidade do curso, a autora postula a existência de três classes de cursos, as quais denominou "cursos seletos", "intermediários" e "populares". Setton (1999, p. 454) adverte que:

A intenção de classificar refere-se apenas a um esforço exploratório para compreender uma realidade heterogênea e complexa - em outras palavras, uma tentativa de síntese que nos permita uma leitura processual e relacionada dos dados obtidos. Procedendo a tal classificação, podemos identificar a composição e o volume dos recursos 
- capital econômico, capital social e capital cultural - dos alunos das unidades investigadas e as vantagens ou não que esses recursos lhes conferem. Também nos permitirá visualizar as semelhanças e as proximidades sociais e acadêmicas dos alunos e seus cursos no espaço universitário.

O estudo de Setton, orientado pela perspectiva investigativa de Bourdieu, distingue cursos no interior de uma mesma instituição com base no volume de vantagens relativas que têm os alunos desta ou daquela unidade. Parece, contudo, que outro viés possível seria aquele que inclua a verificação das formas de organização e de funcionamento das instituições, já que é de supor que a vantagem qualitativa de uma instituição seja um critério importante para a escolha pela matrícula por parte dos estudantes.

É neste contexto que se compreende o aluno "novo" não como um caso particular - como alguém que, por um processo de hiper-seleção, tenha assumido uma posição sócio-institucional que não corresponde à sua de origem -, mas sim como uma condição objetiva de ser estudante no mundo contemporâneo, como algo que afeta e diz respeito a um enorme contingente da população.

Para tanto, é necessário deixar de lado categorias genéricas, como "estudante universitário" ou "universidade brasileira" e tratar de encontrar as linhas de força que constituem o campo em questão.

Assim, é interessante pensar a Educação Superior e as instituições que atuam neste setor com base um conjunto de fatores complementares que permitem perceber como cada uma situa-se no interior do "campo da educação superior", levando em consideração as posições relativas que ocupam os diversos atores, as relações de disputa e de complementaridade e o perfil de estudante que assiste.

Desta forma, ter-se-iam os seguintes aspectos como balizadores da análise:

a) a(s) finalidade(s) da instituição (formação, pesquisa, assistência, etc.) e sua ponderação;

b) sua produção científica, cultural e política;

c) as formas de organização e ocupação do espaço e do tempo institucionais;

d) a localização político-geográfica;

e) seu raio de influência;

f) os processos de administração (incluindo indicação de dirigentes) e de financiamento (incluindo fonte de recursos); 
g) formas de relacionamento com o mercado, com a sociedade e com o Estado;

h) o tipo de público que assiste;

i) o tipo de contrato de trabalho docente;

j) a qualificação docente;

k) a produção científica e intelectual;

1) a relação com centros irradiadores de conhecimento e de exercício do poder.

É neste cenário que faz sentido a caracterização da IES periférica como um modelo específico de instituição no campo da Educação Superior, com as seguintes características:

a) tem finalidade estrita de formação / qualificação de mão de obra;

b) apresenta uma forma de organização e ocupação do espaço e do tempo em que se privilegia espaço/tempo aula;

c) é estruturada com base em modelos mercantis de administração e financiamento

d) apresenta formas de subserviência em relação ao mercado;

e) assiste um público de menor poder aquisitivo e menor disponibilidades culturais e intelectuais;

f) mantém contrato de trabalho docente por hora-aula;

g) a produção intelectual é ocasional e limitada às áreas de menor intensidade científica e baixo custo;

h) tende a atuar como reprodutoras e divulgadoras de conhecimentos pragmáticos, com forte viés de formação ajustada às demandas de mercado.

Este ponto de vista não anula a caracterização institucional destacada por Dias Sobrinho, ao contrário amplia as formas de observação das instituições, de modo a avançar uma caracterização que envolva, principalmente, a circulação e a produção intelectual, bem como as concepções de formação acadêmica envolvidas em políticas administrativas e educacionais e na relação com a sociedade.

A partir do conceito de IES periférica, não se pode dizer que as IES públicas são sinônimas de referência. Do ponto de vista do conhecimento, uma 
instituição pública é passível de encontrar-se periférica, principalmente se localizada muito distante dos centros políticos, econômicos e sociais do Brasil. Nestes casos - em que as disposições de investimento financeiro e intelectual são menores e o número de professores com nível acadêmico de doutorado é também menor -, mesmo que tenham a preocupação com a formação acadêmica voltada para o conhecimento e cumpram outros papéis sociais, como formação de professores e pesquisa na área das Ciências Humanas - estão localizadas à periferia do conhecimento hegemônico, que circula com maior intensidade nas IES centrais de referência.

No que se tange às IES particulares, observa-se que algumas estão localizadas nos centros das grandes cidades brasileiras. Em contrapartida, operam com segmentos periféricos da sociedade, do ponto de vista da política, da economia e da cultura. Pensadas para formar esse segmento da sociedade, atendem as demandas de formação acadêmica exigidas pelo mercado, buscando, prioritariamente, o maior lucro possível, e se constituem, francamente, como empresas de educação. Praticamente não investem em pesquisa e em espaços de circulação e estudo além das salas de aula e corredores; a organização do tempo não viabiliza a fruição dos recursos que a instituição deveria oferecer, de forma que, as atividades como pesquisa e estudos formais pouco ou quase nunca ocorrem.

As IES comunitárias e confessionais, independentemente de serem vistas como instituições de interesse público, ocupam lugar secundário na organização educacional, principalmente a partir de 1990, quando se iniciou de forma aguda o processo de mercantilização da Educação Superior. Essas instituições, mesmo dispondo-se a assumir comprometimento político e com a formação intelectual, vêem-se constrangidas em função da concorrência das universidades empresas.

Aparentemente, no que concerne ao tipo de aluno, as instituições comunitárias e confessionais, em especial as de menor porte e tradição, assistem o mesmo segmento periférico que as privadas. Do ponto de vista do conhecimento, tais Instituições de Ensino Superior são periféricas, pelo público que assistem e, como não dispõe de financiamentos públicos, pela administração que se caracteriza na lógica de mercado.

\section{O "Aluno Novo"}

A hipótese que aqui se sustenta - e que encontra respaldo nos resultados auferidos em trabalhos de anteriores (BRITTO, 2005; 2007; SILVA; BRITTO, 
2004), é a de que a capacidade de estudo, manifestada principalmente pelo uso da escrita e da leitura, está muito mais relacionada às formas de acesso a cultura hegemônica e aos modos de argumentação científica que aos métodos de ensino da educação regular.

Admitindo-se a legitimidade de hipótese acima apresentada, é fundamental verificar, entre outras coisas, como, no universo escolar da Educação Superior contemporânea, este estudante desenvolve formas de relacionar-se com o conhecimento em que se manifestam valores e estratégias de aprendizagem sustentados por um cotidiano limitado e uma experiência escolar cuja organização institucional, ainda que muitas vezes contraditoriamente, parece antes reforçar o pragmático que investir em outras dimensões da aprendizagem.

Neste sentido, compreender um sujeito que está se constituindo pela universidade periférica implica indagar:

a) de que modo o tempo, espaço e comportamento normatizados e esquadrinhos (SANTOS, 2000) se relacionam com as ocupações em função da política e da economia?

b) como se dá a relação entre as formas tradicionais de produção e de circulação do conhecimento e da informação (cultura livresca; modelo liberalburguês de intelectual e de pessoa culta; o papel da formação intelectual na inserção da pessoa a sociedade) e as novas formas de produção e de circulação do conhecimento e da informação (tecnologias computacionais; WEB; posse da produção e comercialização da informação)?

c) que conhecimento "necessário" atende aos métodos, protocolos e procedimentos de produção e consumo na sociedade atual e como se manifesta na luta político-ideológica?

A presença na Educação Superior de número expressivo de estudantes de segmentos sociais que até recentemente pouco não alcançavam este nível de educação implica mais que a simples transformação quantitativa da população universitária.

Freqüentando cursos noturnos de IES de pouco prestígio e de baixa seletividade, esta população estabelece uma relação com estudar e formar-se regida por concepções aligeiradas de conhecimento e fundamentalmente relacionadas à preocupação de qualificação para o mercado de trabalho. Diferentemente do aluno "clássico" - cuja predisposição para estudar supõe vínculos claros com idade, disponibilidade de tempo, formação escolar e intelectual, capital 
cultural, financiamento familiar -, o aluno universitário "novo", em grande parte pertencente à primeira geração de longa escolaridade e oriundo de um segmento social cuja expectativa primeira é formar-se para o mercado de trabalho de nível médio, não dispõe de condições apropriadas para estudar, tem formação escolar primaria e média insuficiente e pouca convivência com os objetos intelectuais e artísticos da cultura hegemônica; além disso, mais frequentemente trabalha durante o dia e assiste a cursos noturnos ${ }^{3}$, com pouca disponibilidade de tempo e recursos para participar de atividades acadêmicas que transcendam o espaço-aula, raramente participando de atividades de extensão cultural, atividades de pesquisa, encontros científicos, etc. Tais fatores, apesar de mais freqüentemente não serem supridos pela educação escolar, repercutem intensamente nas práticas intelectuais e nas avaliações que se realizam em seu interior. (BOURDIEU, 1998)

Enfim, pode-se dizer que o "novo aluno" não busca, em que pese a ideologia contrária, a Educação Superior para mudar de condição econômica, social e intelectual, não dispõe de condições objetivas suficientes para estudar e apresenta formação que não satisfaz as expectativas acadêmicas. Comumente se lêem reportagem em que se destaca sua incompetência, a má escrita e a dificuldade de leitura.

Esta realidade desautoriza considerar o estudante universitário (ou um segmento expressivo dele), bem como sua aprendizagem, em termos "clássicos". O estudante clássico (cuja imagem prevalece como "modelo" nos meios acadêmicos) dispõe de tempo para estudar; tem idade, formação intelectual que transcende aos conteúdos escolares, financiamento familiar, disposição para atividades diversificadas social e culturalmente. Enfim, pertence a um segmento privilegiado da sociedade e trabalham para a manutenção ou melhoria de sua condição social. São características que coadunam com as exigências acadêmicas.

Em outras palavras, as dificuldades no trato com o conhecimento e as formas de exposição acadêmicas não adviriam da falta de uma capacidade genérica, mas sim do modo como os sujeitos interagem e convivem com o conhecimento formal. O que se pôde notar nos resultados das pesquisas anteriores é que as estratégias e procedimentos de estudo mais freqüentes, bem como a representação que têm de verdade, estão sustentados por formas de conhecimento típicas do saber pragmático, em que predomina o senso comum.

3 Em estudo sobre o estudante universitário e o trabalho, Cardoso e Sampaio (1994, p. 1), assumem que "o que está por trás desse tipo de análise é a idéia de que trabalho e estudo são situações mutuamente excludentes. Nem a formação de nível superior faz parte do universo dos jovens trabalhadores nem o trabalho é cogitado pelos jovens universitários". 
Conforme, Hansen (1989, p. 137), que analisou a produção textual de alunos de uma faculdade noturna na década de 1980 ,

O aluno parece possuir, como um saber implícito, que, na relação intersubjetiva criada pelo discurso, a intenção é dizer algo dizendo sobre algo - essa dupla orientação de uma visada ideal (dizer algo) e de uma referência real (sobre algo) só encontra efetivação satisfatória na operação com a referência, que, por sua vez, é sempre imediata, concreta, "prática", descritiva, metonímica, metafórica.

A análise de Hansen, realizada em um contexto algo distinto do atual, mas em que já se verificava a tensão entre as concepções e formas de realização do conhecimento e de estudo por parte de estudantes que não se ajustavam ao perfil clássico. É bastante razoável supor que, com a intensa ampliação e massificação da Educação Superior produzida nas décadas seguintes tornaram a questão ainda mais aguda e complexa.

Admitindo a legitimidade de hipótese enunciada, é essencial verificar, entre outras coisas, como, no cotidiano escolar da Educação Superior contemporânea este estudante desenvolve ou não desenvolve novas formas de relacionar-se com o conhecimento em que se tensionam os valores e as estratégias de aprendizagem sustentadas por um cotidiano limitado e em experiência escolares cuja própria organização institucional, ainda que muitas vezes contraditoriamente, parece antes reforçar o pragmático que investir em outras dimensões da aprendizagem e da ação.

Estaremos, desta forma, progredindo no entendimento objetivo das formas como a educação escolar - em particular, a educação superior - vem se conformando às novas demandas e imposições de ordem econômico e política para a formação acadêmica e profissional.

\section{Referências}

BOURDIEU, Pierre. Escritos em educação. Seleção, organização, introdução e notas Maria Alice Nogueira; Afrânio Catani. Petrópolis: Vozes, 1998.

BOURDIEU, Pierre. Os usos sociais da ciência - por uma sociologia clínica do campo científico. São Paulo: Editora Unesp, 2003. 
BRITTO, Luiz Percival Leme. Conhecimento e formação na universidade periférica - problemas teóricos e metodológicos. In: ENCONTRO DE PESQUISA EM EDUCAÇÃO DA REGIÃO SUDESTE, 8, 2007, Vitória, ES. Anais... Vitória, ES: UFES, 2007. 1 CD-rom.

BRITTO, Luiz Percival Leme. Leitura de estudo de estudantes universitários de IES periférica - uma aproximação. Avaliação: Revista de Avaliação da Educação Superior, Campinas, v. 10, n. 4, p. 105-126, dez. 2005.

BRITTO, Luiz Percival Leme. Leitura e escrita de estudantes universitários. In: Contra o consenso: cultura escrita, educação e participação. Campinas: Mercado de Letras, Campinas, 2003. p. 175-194.

BRITTO, Luiz Percival Leme; TOREZAN, Ana Maria. Estratégias de aprendizagem utilizadas em atividades de estudo por estudantes universitários de primeira geração de longa escolaridade. Sorocaba: Uniso, 2002. Projeto de pesquisa FAPESP

CARDOSO, Ruth C. L; SAMPAIO Helena. Estudantes universitários e o trabalho. Revista Brasileira de Ciências Sociais, 1994. Disponível em: www.anpocs.org.br. Acesso em: 25/08/2008.

CASTANHO, Sérgio. A universidade entre o sim, o não e o talvez. In: VEIGA, I.; CASTANHO, M. (Orgs.). Pedagogia universitária: a aula em foco. Campinas: Papirus, 2000.

CHAUÍ, Marilena. Escritos sobre a universidade. São Paulo: Editora da Unesp, 2001.

CUNHA, Luiz Antônio. Desenvolvimento desigual e combinado no ensino superior - estado e mercado. Educação \& Sociedade, Campinas, v. 25, n. 88 especial, p. 795-817, out. 2004.

DIAS SOBRINHO, José. Avaliação ética e política em função da educação como direito público ou como mercadoria? Educação \& Sociedade, Campinas, v. 25 , n. 88 , out. 2004. p. 36-40.

DIAS SOBRINHO, José. Universidade e avaliação: entre a ética e o mercado. Florianópolis: Insular, 2002.

DIAS SOBRINHO, José; GOERGEN, Pedro. Compromiso Social de la Educación Superior. In: TRES, Joaquim; SANYAL, Bikas C.; LÓPEZ-SEGRERA, Francisco. (Org.). La educación superior en el mundo 2007. Acreditación para la garantía de la calidad: ?Qué está en juego?. Madrid-Barcelona: Ediciones Mundi-Prensa GUNI Unesco, 2006. v.1, p. XXXVI-XL. 
GOERGEN, Pedro. Ciência, sociedade e universidade. Educação \& Sociedade, Campinas, v. 19, n. 63, ago. 1998.

HADDAD, Sérgio; GRACIANO, Mariangela. Educação direito universal ou mercado em expansão. São Paulo em Perspectiva, São Paulo, v. 18, n. 3, p. 67-77, jul./set. 2004.

HANSEN, João Adolfo. O desempenho em redação. In SPOSITO, Marília Pontes (Coord.) O trabalhador estudante: um perfil do aluno do curso superior noturno. São Paulo: Loyola, 1989.

MANCEBO, Deise. Reforma universitária: reflexões sobre a privatização e a mercantilização do conhecimento. Educação \& Sociedade, Campinas, v. 25, n. 88 , out. 2004 .

SANTOS, M. Território e sociedade: entrevista com Milton Santos. São Paulo: Fundação Perseu Abramo, 2000.

SETTON, Maria da Graça Jacintho. A divisão interna no campo universitário: uma tentativa de classificação. Revista Brasileira de Estudos Pedagógicos, Brasília, v. 80, n. 195, p. 451-471, set./dez. 1999.

SETTON, Maria da Graça Jacintho. Um novo capital cultural: pré-disposições e disposições à cultura informal nos segmentos com baixa escolaridade. Educação \& Sociedade, Campinas, v. 25, n. 90, p. 77-105, jan/abr. 2005.

SGUISSARDI, Valdemar. Universidade pública estatal: entre o público e privado/ mercantil. Educação \& Sociedade, Campinas, v. 26, n. 90, p. 191 -222, jan./abr. 2005.

SILVA, Ivanilson Bezerra; BRITTO, Luiz Percival Leme. Uso da biblioteca por estudantes de Educação Superior. Série-estudos, Campo Grande, v. 18, n. 2, p. 265-280, jul. 2004.

SILVA, Marco Wandercil; BALZAN, Newton César. Universidade corporativa: (pré-) tendência do Ensino Superior ou ameaça?. Avaliação: Revista de Avaliação da Educação Superior, Campinas, v. 12, n. 2, p. 233-256, jun. 2007.

VIEIRA, Luiz Renato. A expansão do ensino superior no Brasil: abordagem preliminar das políticas públicas e perspectivas para o ensino de graduação. Avaliação: Revista de Avaliação da Educação Superior, Campinas, v. 8, n. 2, p. 81-98, jun. 2003 . 
ZAGO, Nadir. Do acesso à permanência no ensino superior: percursos de estudantes universitários de camadas populares. Revista Brasileira de Educação, São Paulo, v. 11, n. 32, p. 226-237, maio/ago. 2006. 